\title{
INFLUENCE OF ALKALI TREATMENTS ON THE SURFACE CHARACTERISTICS OF NIGERIAN SISAL FIBRE
}

\author{
E.S. Nwadiokwu \\ Chemical, Fibre and Environmental Technology Department, \\ Federal Institute of Industrial Research, Oshodi (FIIRO), \\ P.M.B. 21023, Ikeja, Lagos, Nigeria. \\ esnwadiokwu@gmail.com
}

\begin{abstract}
The influence of alkali modification on the surface characteristics of Nigerian sisal fibres has been studied. The sisal fibres were chemically modified using different concentrations of caustic soda while varying the treatment time. Treated and untreated samples were investigated for their surface characteristics based on their SEM photo micrographs. The alkali treatments were found to have significant effects on the surface characteristics of the fibres. SEM micrographs revealed the rough surface topography of the sisal fibres caused by alkali modification which increased with increase in alkali concentration. The time of treatment appear not to have any significant effect on the surface topography investigated.
\end{abstract}

Keywords: Sisal Fibres, Surface characteristics, Alkali treatment, Alkali modification 


\subsection{INTRODUCTION}

Sisal fibre is a hard fibre extracted from the leaves of sisal plant (Agave sisalana). Though native to tropical and subtropical North and South America, sisal plants are now widely grown in tropical countries of Africa, the West Indies and the Far East (Bisanda et al., 1994). Tanzania and Brazil are the two major producing countries in Africa and South America (Chand et al, 1998).

Using sisal fibre as reinforcement in composites has raised great interest and expectations among Materials Scientists and Engineers (Bledzki et al, 1996). However, sisal fibre reinforced composites generally have poor interface (Bledzki et al, 1999). This is because, sisal fibre is lignocellulosic in nature; the presence of a large amount of hydroxyl groups is responsible for the hydrophilic nature of sisal fibre.

Several fibre surface treatment methods have been studied to improve the adhesion properties between sisal fibres and a surrounding matrix. An effective method includes alkali treatment to increase the roughness of fibre surface hence increasing the surface area available for contact with matrix.

In this paper, alkali treatment was used to chemically modify sisal fibres using different concentrations of sodium hydroxide $(5 \%, 10 \%, 15 \%$ and $20 \%)$ and at different times of treatment (5mins, 10mins and 15mins). The effects of this modification on the surface characteristics were assessed and analyzed.

\subsection{MATERIALS AND METHODS}

\subsection{Materials}

The main materials for this study were sisal fibres obtained from the Botanical garden of the Ahmadu Bello University, Zaria.

\subsection{Chemicals}

Aqueous sodium hydroxide solution $(5,10,15$ and $20 \%$ by weight) and acetic acid (2\% by weight).

\subsection{Equipment/Instrumentation}

The following equipment/instruments were used for the study: Scanning Electron Microscope (EVO MA10 CARL ZEISS, high resolution SEM), basic laboratory glassware, such as, conical flasks, beakers, measuring cylinders, thermometer, stirring rod, and volumetric flask

\subsection{METHODS}

\subsubsection{Extraction of the Sisal Fibres}

The sisal leaves were crushed and beaten manually by a smooth edged stick so that only fibres remain. After extraction, the fibres were washed thoroughly in water to remove surplus wastes 
such as chlorophyll, leaf juices and adhesive solids (hemicelluloses). The fibres were then dried in open air. The dried sisal fibre strands are found to be creamy white in colour.

\subsubsection{Chemical Modification of the Fibres}

2 grams of the sisal fibres were soaked in 5, 10, 15 and $20 \%$ sodium hydroxide solution for 5, 10 and 15 minutes at a temperature of $65^{\circ} \mathrm{C}$. These fibres were further rinsed with water followed by neutralization in $2 \%$ acetic acid solution. The fibre strands were finally rinsed in water and then dried at room temperature.

Sisal-OH $+\mathrm{NaOH} \rightarrow$ Sisal- $\mathrm{O}^{-} \mathrm{Na}^{+}+\mathrm{H}_{2} \mathrm{O}$

\subsubsection{Determination of Surface Characteristics}

The nature of the surface of the sisal fibre is very important as this determines to a large extent the properties of the fibre. In order to evaluate changes in the surface morphology, the surface characteristics of untreated and chemically modified sisal fibres were studied using the Scanning Electron Microscope (SEM). The SEM micrographs were used to study the surface of the unmodified sisal fibre as compared to the surface of the chemically modified fibres. The results obtained are presented on plates I to VII

\subsection{RESULTS AND DISCUSSION}

\subsection{ASSESSMENT OF SURFACE CHARACTERISTICS}

The scanning electron microscope was used for these tests at different concentrations and time. The time was kept constant at 5 minutes, 10 minutes and 15 minutes. For each constant time, the concentration of sodium hydroxide was varied at 5\%,10\%, 15\% and $20 \%$.

The concentration of sodium hydroxide was also kept constant at 5\%, 10\% 15\% and 20\%. For each constant concentration of sodium hydroxide, the time was varied at 5 minutes, 10 minutes and 15 minutes respectively. The SEM micrographs obtained are displayed on plates I to VII.

Plates Ia to VIIa show that the surface of the unmodified sisal fibre is wrapped with some "cementing" substances. These substances covered the residual lignin, pectins, hemicelluloses, waxes and oils. However, from Plates I to III, it can be seen that the alkali treatment removed the "cementing substances" which led to the formation of a rough surface topography as viewed from the SEM micrographs. The degree of roughness is according to the extent of the alkali modification of the fibres. This means that increase in the concentration of caustic soda, increases the roughness of the fibre surface. This increases the effective surface area available for wetting by the polymer matrix. The rough surface is made up of pits which are circular holes of about $1 \mu \mathrm{m}$ in diameter. These pits are responsible for transporting water and nutrients throughout various cells to the roots and leaves of cellulose-containing plants. However from plates IV to VII, increase in time of modification does not have much effect on the surface characteristics of the sisal fibres. This is because the increase in surface roughness due to higher timing is minimal. 


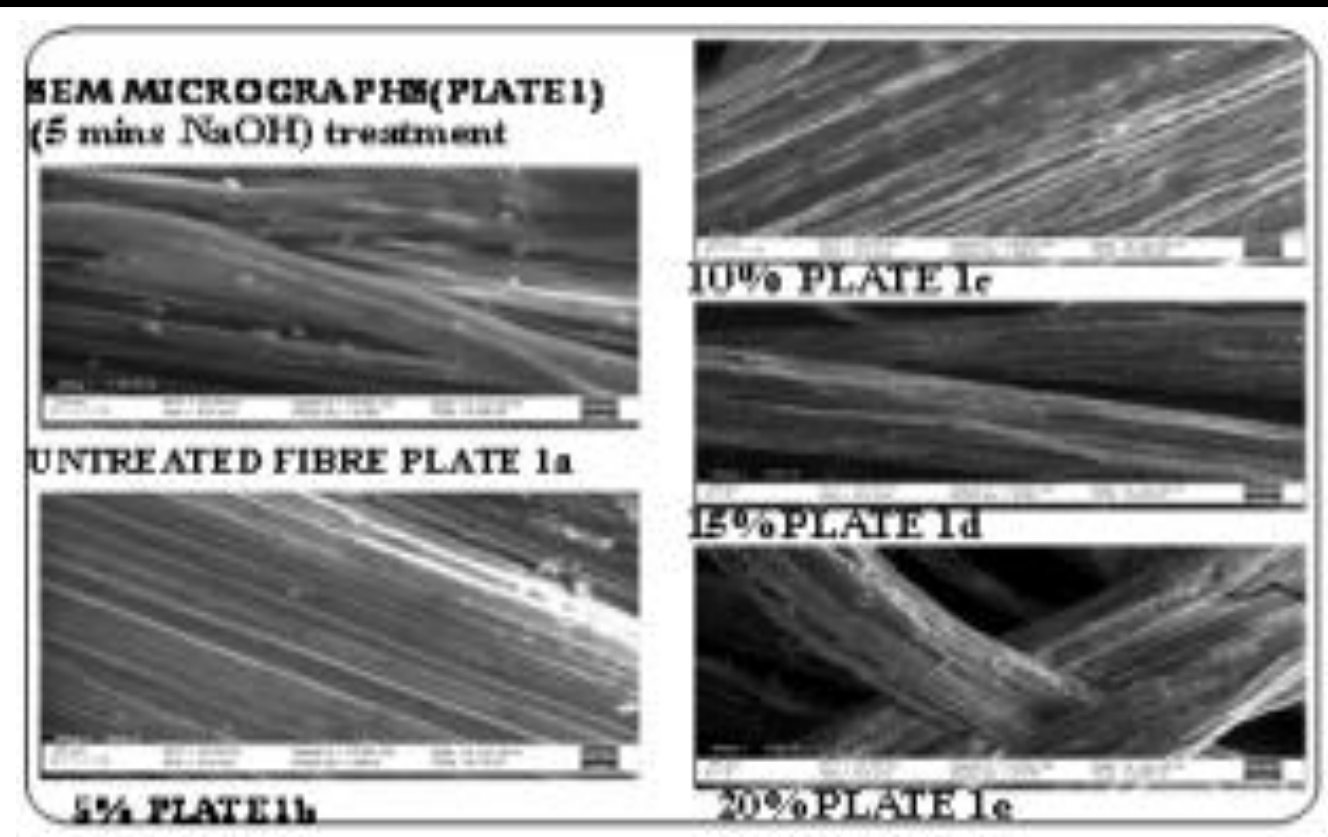

Plate I: Treatment with sodium hydroxide for 5 minutes at different concentrations

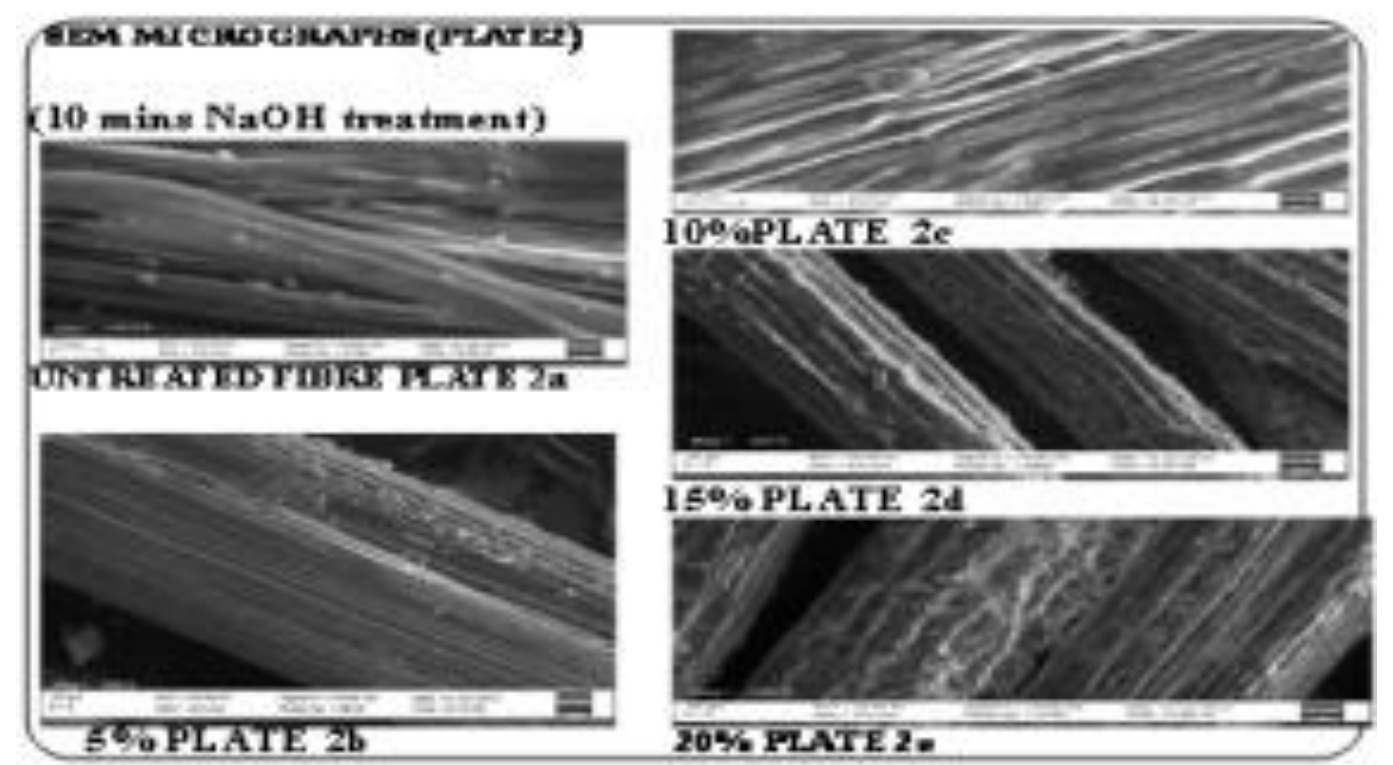

Plate II: Treatment with sodium hydroxide for 10 minutes at different concentrations 


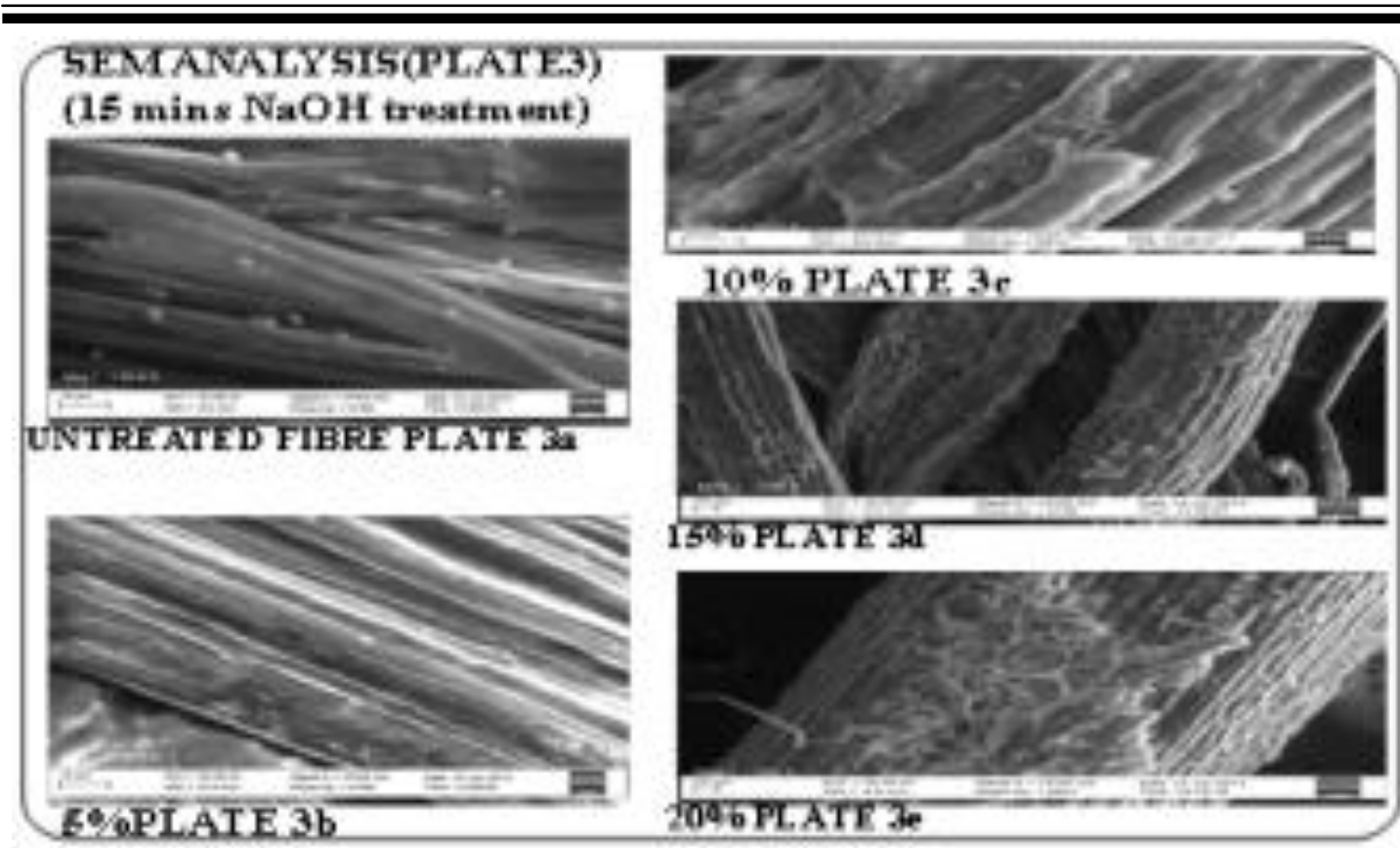

Plate III: Treatment with sodium hydroxide for $\mathbf{1 5}$ minutes at different concentrations

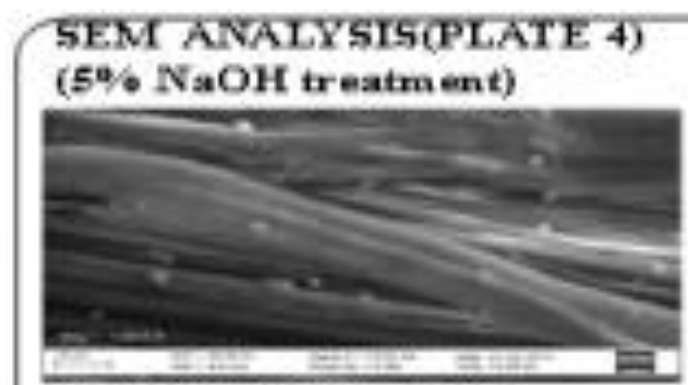

UTT REAT ED FIATE A

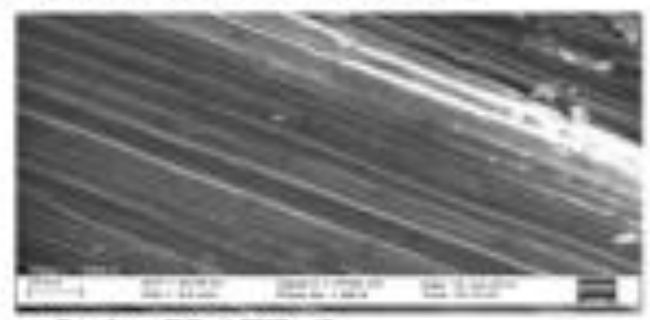

Smins PI, ATE $4 \mathrm{~b}$

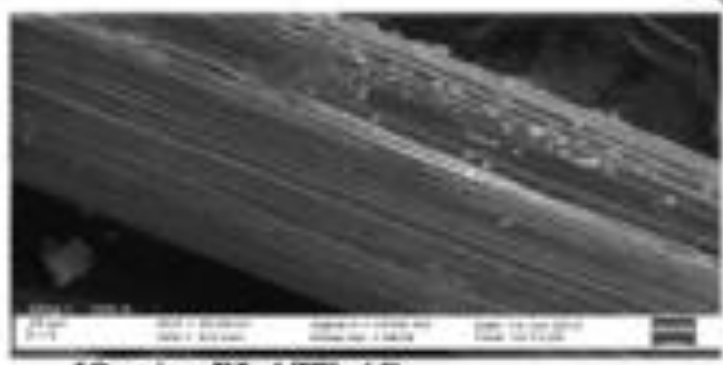

10 mins PL ATE $4 \mathrm{C}$

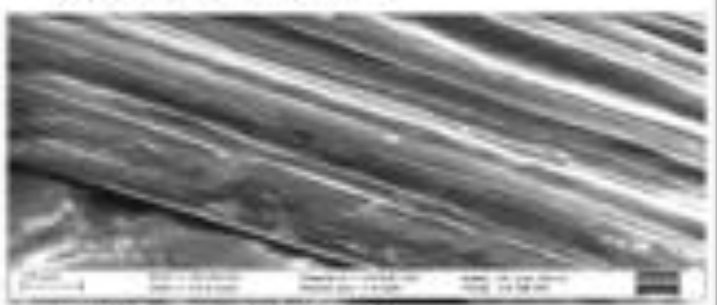

15 mins PL ATE 4 d

Plate IV: Treatment with sodium hydroxide at $5 \%$ concentration for different times 


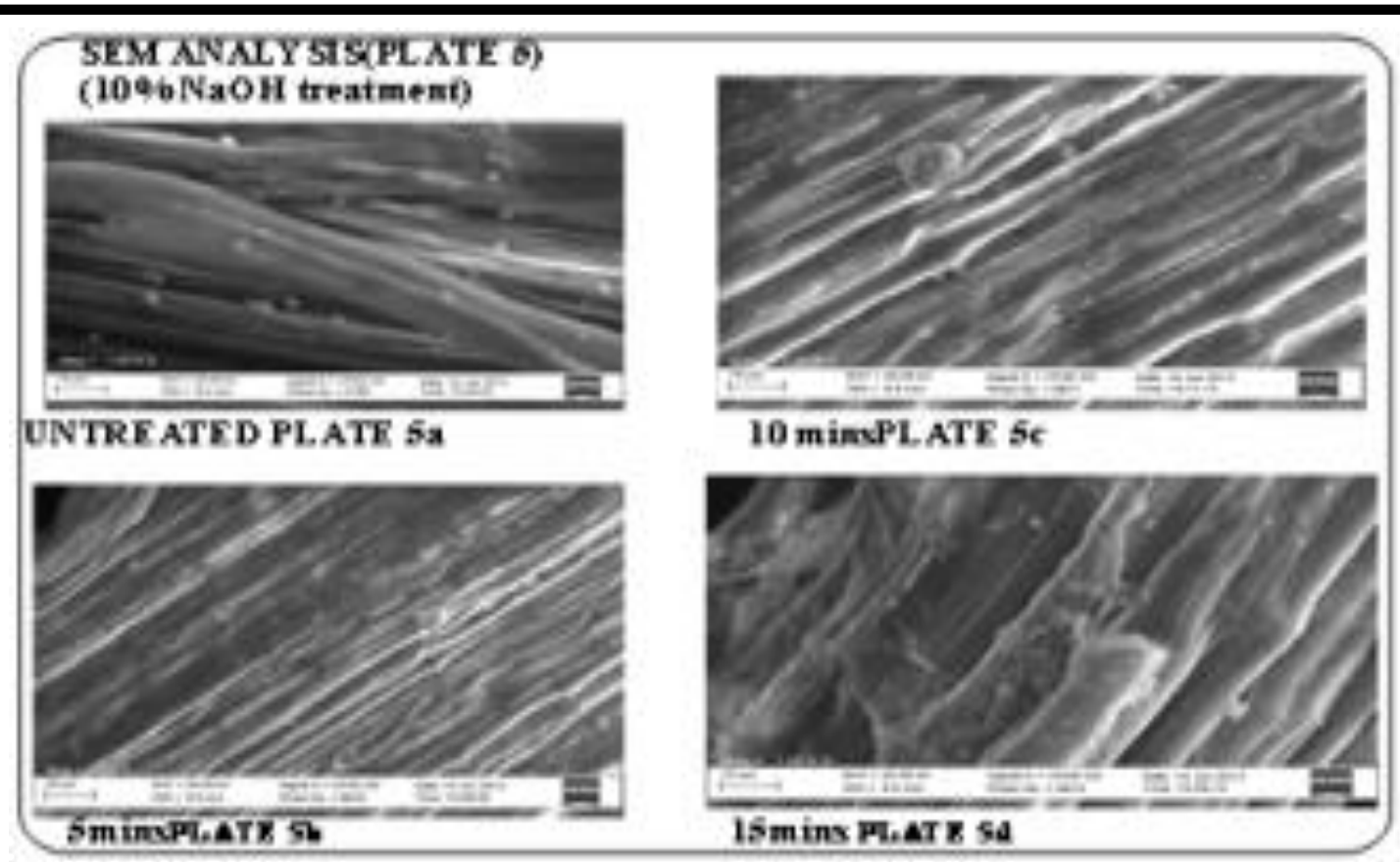

Plate V: Treatment with sodium hydroxide at $10 \%$ concentration for different times

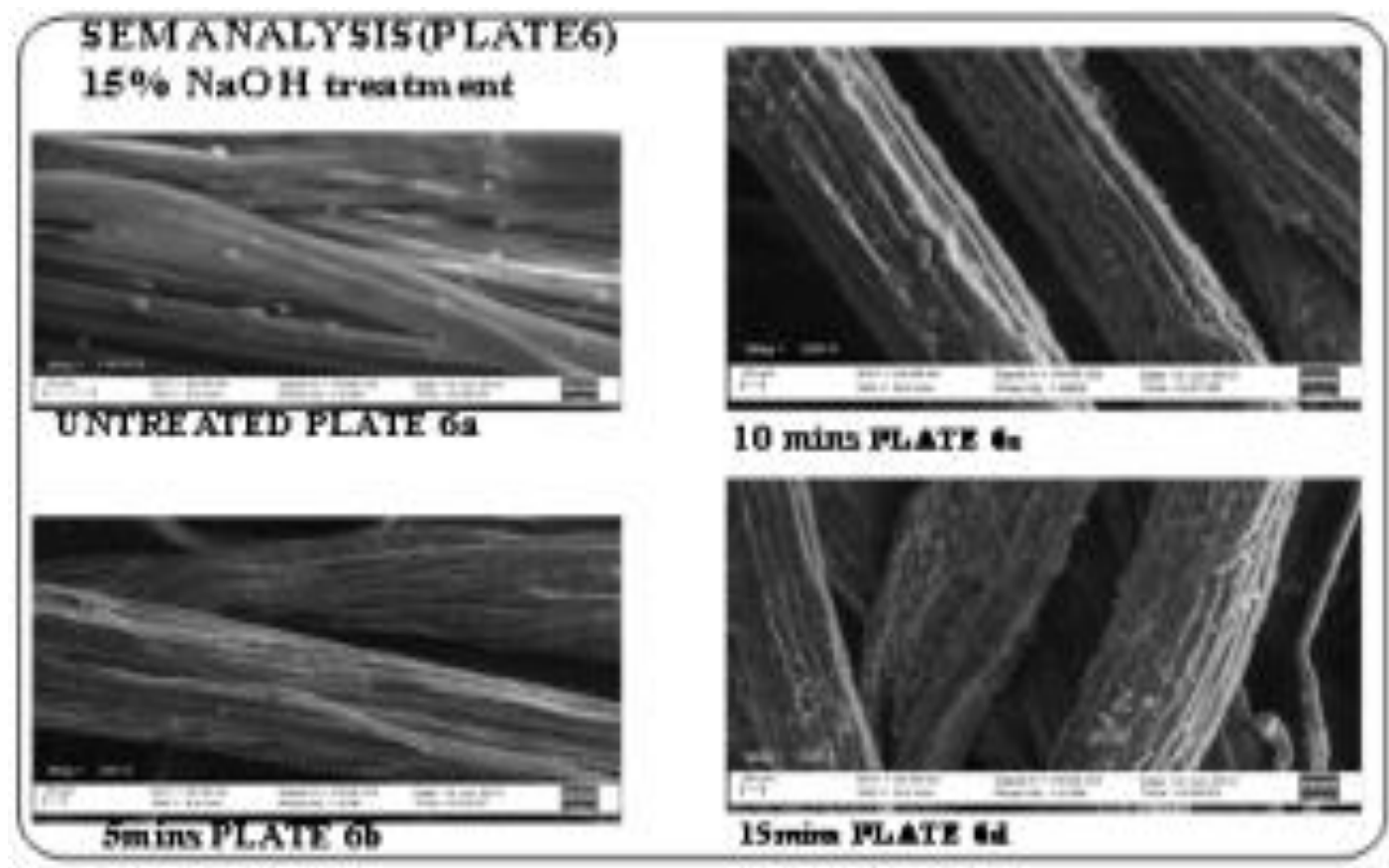

Plate VI: Treatment with sodium hydroxide at $15 \%$ concentration for different times 


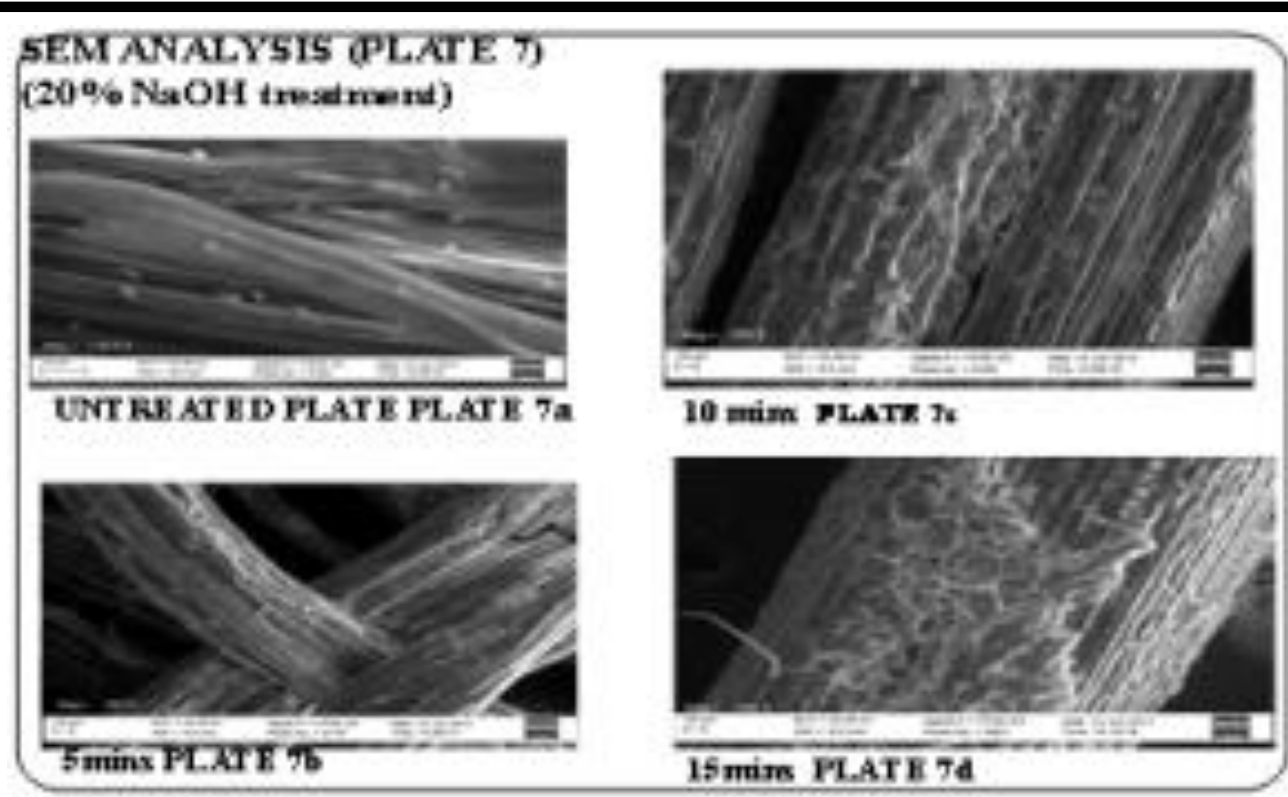

Plate VII: Treatment with sodium hydroxide at $20 \%$ concentration for different times

\section{CONCLUSION}

Several chemical modifications such as alkalization, acetylation, silane treatment, titane treatment etc. have been known to change the surface morphology of natural cellulosic fibres. However for the purpose of this study, alkali treatment was employed because of its unique effects on fibres and it is cheap and readily available compared to the other types of treatments. It was observed that the surface of the sisal fibres before modification was relatively smooth and filled with constituents such as hemicelluloses, waxes, lignin, pectin etc covered up by cementing materials, but alkali treatment at various percentage concentrations $(5 \%, 10 \%, 15 \%$ and 20\%), and at different timing (5minutes, 10minutes and 15minutes) carried out on the sisal fibres, removed the impurities inside the fibres according to the degree of alkali concentration and thereby creating a rough surface morphology as shown by the SEM Micrographs. It was also noted that increase in the concentration of alkali increases the roughness of the fibre surface.

However, increase in time of modification does not have much effect on the surface characteristics of the sisal fibres investigated as shown by the SEM micrograph. 


\section{REFERENCES}

Bisanda E. T. N. and Ansell, M. P. (1994) Journal of Material Science, pp. 27.

Bledzki, A.K., Reihmane, S. and Gassan, J. (1996). Applied Polymer Science, 5, 1329

Bledzki, A. K., and Gassan, J. (1999) Natural Fiber Reinforced Plastics, in Handbook of Engineering Polymeric Materials, ed. N. P. Cheremisinoff, Marcel Dekker, New York, pp. 787-810.

Chand N., Tiwary, R. K. and Rohatgi, P. K. (1998).Journal of Material Sciences, pp.23 